\title{
¿QUÉ TAN VIEJOS SON ESTOS HUESOS? PUTNAM, WITTGENSTEIN Y LA VERIFICACIÓN
}

Cora Diamond

UNIVERSIDAD DE VIRGINIA

Así pues, es como si la prueba no determinase el sentido de la proposición probada $y$, sin embargo, como si sí lo determinase.

Pero, ino sucede lo mismo con cualquier verificación de cualquier proposición?*

En este escrito considero un caso inventado por Hilary Putnam. ${ }^{1}$

Allá en el siglo XVII se desenterraron huesos extraños en Whoozie y alguien se pregunta qué tan viejos son los huesos. Nosotros sabemos que tienen más de un millón de años; nosotros tenemos técnicas, técnicas del siglo XX, que han establecido su edad. En la época de Newton no había tales técnicas. Pero, supongamos que alguien hubiese especulado acerca de la edad de los huesos. Putnam dice que aun si esta persona hubiese considerado la idea de que los huesos tuviesen un millón de años, ella habría acertado y si la hubiese rechazado como absurda, habría estado equivocada. (Puesto que me referiré muchas veces a este especulador, le he dado un nombre: Leibniz.)

Putnam inventó el caso cuando estaba estudiando a Richard Rorty; ${ }^{2}$ necesito explicar brevemente cuál era el problema.

Rorty nos recomienda una forma particular de hablar acerca de la verdad y de la falsedad. Así, por ejemplo, dice que si la oración en latín que Newton usó en el siglo XVII para enunciar el principio de inercia, la hubiese emitido

* Wittgenstein, Remarks on the Foundations of Mathematics, Oxford, 1978, pp. 312-313.

1 Hilary Putnam, "Newton in His Time and Ours: Will the Real Richard Rorty Please Stand Up?", manuscrito. Me refiero a este escrito como NTO.

[Por la importancia que en este artículo tiene la expresión "significado" u otras expresiones de la misma familia, en los casos en los que en el original figuraba la palabra "meaning" o algu na palabra relacionada y que al traducirla normalmente no usariamos "significa" o alguna otra palabra afin, he añadido, entre paréntesis, la expresión pertinente de la familia; así, por ejemplo, en casos como "What do you mean?" la traducción ha sido "¿Qué quieres decir (significar)?" N.T.]

2 Richard Rorty, “Were Newton's Laws True Before Newton?”, manuscrito, 7/VIII/87, véanse especialmente pp. 5-7. 
alguien en el siglo XX, no habría sido, entonces, una candidata de valor de verdad, entonces no habría sido verdadera o falsa. Se convirtió en candidata para ser verdadera o falsa cuando se desarrolló un conjunto de prácticas coherentes y útiles dentro de las que podrían encajarse usos de esa oración para hacer aseveraciones.

Si seguimos la recomendación de Rorty, diríamos que la oración "Los huesos que se encontraron en Whoozie tienen un millón de años” se convirtió en candidata para ser verdadera o falsa durante el siglo XX y, así, parece que hemos de rechazar la idea de Putnam de que si Leibniz dijo que los huesos tenían un millón de años, él estuvo acertado acerca de algo.

Putnam reconoce que hay una réplica que Rorty podría dar. Si decimos de la oración, "Los huesos de Whoozie tienen un millón de años", que no se hace verdadera en el siglo $\mathrm{XX}$, sino que era verdadera incluso en la época de Leibniz, tan sólo estamos haciendo un elogio postleibniziano a nosotros mismos. Pero, arguye Putnam, esto no funcionará. Él no sólo está interesado en nuestro discurrir de siglo XX acerca de la oración, sino también en lo que quiere decir que la gente sea capaz de comunicarse una con otra, incluso a través de épocas en las que hay cambios radicales en técnicas de investigación. La observación que Putnam deseaba hacer sobre Leibniz, que había acertado acerca de la edad de los huesos, pretende, entonces, ser más que un mero elogio de la oración de Leibniz (entendida a nuestra manera). Lo que Leibniz pensó, adivinó, es lo que nosotros ahora sabemos que es así. (Se podría decir que se enlazan su adivinanza y nuestro conocimiento.)

¿Cómo es que Wittgenstein encaja en esto? Putnam, en parte, explica su respuesta a Rorty mediante un contraste entre las tesis de Wittgenstein y las que Norman Malcolm le adscribió a Wittgenstein. Tal como Malcolm leyó a Wittgenstein, éste identificó significado con uso en un juego de lenguaje y pensó en los juegos de lenguaje como cuerpos cerrados de prácticas. Conforme a ese tipo de lectura, cada vez que se inventa una nueva forma de verificar una oración, ésta cambia de significado. Así, Wittgenstein se lee como si fuera un verificacionista extremo.

Volviendo a la expresión de Leibniz, "Estos huesos tienen al menos un millón de años", podemos formular una aseveración malcolmiana: la oración acerca de los huesos no podía, en los días de Leibniz, haberse usado para hacer el enunciado que hacemos cuando usamos esas palabras hoy $(N T O$, p. 3). Entonces no había prácticas de investigación dentro de las que estuviese encajada la oración. Los juegos de lenguaje del siglo XVII con datación de sucesos y establecimiento de las edades de los objetos, no podían llegar a ninguna oración como la de que los huesos tuviesen un millón de años. Puesto que en nuestro 
uso de la oración estamos jugando un juego de lenguaje muy diferente de cualquiera que existiese en el siglo XVII, ahora la oración tiene un significado diferente. $^{3}$

Ese argumento, dice Putnam, se basa en una fatigada pseudofilosofía wittgensteiniana del lenguaje; Wittgenstein mismo no pensó que una diferencia en el uso, en las técnicas de investigación, implicase que debe haber una diferencia correspondiente en el significado.

Putnam usa el contraste entre las tesis de Wittgenstein, tal como él las entiende, y la fatigada pseudofilosofia wittgensteiniana del lenguaje para formularle su pregunta a Rorty. Si Rorty no está intentando devolvernos algo como el fatigado pseudowittgensteinismo, si está dispuesto a conceder que el significado sea compartido por personas que no necesariamente comparten técnicas de investigación, entonces, ¿cuál, exactamente, puede ser la fuerza de la recomendación de Rorty de que tratemos las leyes de Newton como si se convirtiesen en candidatas para tener valores de verdad sólo a través de las obras de Galileo y de Newton? La recomendación sería el fatigado pseudowittgensteinismo si nos lleva a negar que podríamos concordar con Leibniz acerca de los huesos y nos deja, en lugar de esto, tan sólo tomando la oración de Leibniz y pegándole nuestros usos honoríficos de "verdadero", "correcto", "acertado". El fatigado pseudowittgensteinismo nos dejaría a nosotros y a Leibniz hablando lenguajes "inconmensurables". Pero, si Rorty no es un wittgensteiniano fatigado, entonces concederá que las oraciones no cambian su significado con cada cambio en técnicas de investigación. Él concederá que no tan sólo reconocemos la oración del siglo XVII como que coincide verbalmente con una oración que nosotros llamamos verdadera; nosotros la entendemos -emitida entonces- así como la entendemos emitida hoy. Sus condiciones de verdad no han cambiado; tan sólo sucede que ahora sabemos que era verdadera. ¿Cómo es que Rorty no llega a decir eso si no es un

3 Hay una ligera complicación que surge del argumento. Anteriormente hablé de Leibniz como especulando. Esto es, la oración, tal como él la usa, expresa una conjetura o una apuesta más bien que un enunciado de que algo es así. Al dar el argumento malcolmiano, sigo a Putnam al hablar del enunciado formulado en el siglo XVII mediante un uso de la oración acerca de la edad de los huesos. Si alguien, al usar la oración en el siglo XVII estuviese enunciando, a diferencia de adivinando, que los huesos tenían un millón de años, se necesitarian satisfacer más condiciones. Quizás la persona considera que Dios le ha dicho en un sueño que los huesos tienen un millón de años y, así, asevera, “Tienen un millón de años”. La palabra 'enunciado' puede usarse en una forma mucho más general, de tal manera que cubra una amplia clase de usos de oraciones indicativas. Pero éste es un uso filosófico especializado de "enunciado" que, quizás, pueda delimitarse sólo vía los términos ("candidara de valor de verdad" y demás) que están en disputa en el debate entre Putnam y Rorty. Estos problemas acerca de formulación de enunciados, pueden evitarse. Pues la propuesta que Putnam necesita es simplemente que una conjetura formulada en el siglo XVII hábría sido correcta. Los problemas acerca de la comunicación, centrales para Putnam, aún surgen y pueden formularse totalmente en términos de la idea que Leibniz consideraba o en términos de la cuestión que se formuló a sí mismo acerca de la edad de los huesos. 
pseudowittgensteiniano fatigado? Y, ¿qué puede significar decir que la oración no fue antes candidata de valor de verdad, si no se pretende negar esa manera de comprender la situación?

\section{III}

¿Fue Wittgenstein un wittgensteiniano fatigado? Ésta es la pregunta que ahora considero, porque puede ayudarnos a entender las preguntas acerca del significado y la comprensión formuladas por Putnam. En esta sección analizo las razones de Putnam para negar que Wittgenstein era un wittgensteiniano fatigado.

Putnam apela a las "Conferencias sobre la creencia religiosa" de Wittgenstein como una base para decir que Wittgenstein no identificó toda diferencia en el uso de una palabra con una diferencia en el significado. El pasaje pertinente en las conferencias es sorprendente y nada claro. De dos personas cuyo uso de las palabras es muy diferente, en conexión con la idea de un juicio final, Wittgenstein dice, primero, que se podría expresar esa diferencia diciendo que una de ellas quiere decir (significa) algo totalmente diferente de la otra y luego dice que la diferencia podría no mostrarse en ninguna explicación del significado. Esto es, la explicación del significado no sería una explicación que estuviese ligada a un uso más bien que al otro. Putnam lee este pasaje como si en él la primera observación, la que supuestamente "tú" podrías hacer, acerca de que las dos personas no quieren decir lo mismo (no expresan los mismos significados), la hiciese un interlocutor a quien luego Wittgenstein le recuerda, hablando en propria persona, que no es así como usamos la palabra "significado"; la explicación del significado es la misma; así que (ésta es la implicación que Putnam ve) diríamos que las dos personas quieren decir lo mismo (expresan los mismos significados). ${ }^{4}$

La conferencia, como una totalidad, sugiere una lectura algo diferente. Wittgenstein arguye que nuestras formas ordinarias de hablar acerca del significado y la comprensión no nos ayudan en los tipos de casos analizados en la conferencia. ${ }^{5}$ Él no está a favor de decir o bien que los dos hablantes imaginados quieren decir lo mismo (expresan el mismo significado) o bien que no lo hacen; así como, más adelante en la conferencia, tampoco está a favor de decir (en un caso similar) o bien que los dos hablantes se comprenden o que no se comprenden el uno al otro. Sugiero que, en el trasfondo del pasaje al que se

4 Que ésta es la comprensión que tiene Putnam del pasaje, no se hace explícito en NTO, pero se aclara en su "Wittgenstein on Religious Belief", en Leroy S. Rouner (comp.), On Community, Notre Dame (Indiana), 1991, pp. 63-64.

5 Ciertamente esta propuesta la presenta claramente Putnam en "Wittgenstein on Religious Belief", p. 64. Pero no la usa para cuestionar, como yo lo haría, la lectura del pasaje acerca de la diferencia en significado. 
refiere Putnam, hay un rasgo importante de nuestra relación con muchas expresiones, a saber, que una vez que se nos da una explicación del significado, pasamos a emplear la expresión de maneras muy similares; no nos movemos en diferentes direcciones. En el caso que Wittgenstein está describiendo, falta esa respuesta normal a la explicación del significado. Y por esto tenemos las dos reacciones contrastantes ante el caso, a saber, una inclinación a decir, si pensamos acerca de la diferencia total en el uso, que las dos personas no quieren decir lo mismo (no expresan el mismo significado) y una inclinación a decir, si notamos que no hay aquí dos explicaciones diferentes del significado, que el significado es el mismo.

En una conferencia posterior de la misma serie, Wittgenstein habló de la palabra "muerte" y lo que significa tener una idea de la muerte. Lo que comúnmente se llama 'tener una idea' tiene una referencia a la técnica de la palabra. Es una palabra pública, ligada a toda una técnica. Si alguien dice que tiene su propia idea de la muerte y no está ligada a la técnica pública, Wittgenstein dice que podríamos preguntar qué derecho tiene él en llamarla una idea de la muerte. Tal como él habla de ella, no pertenece al juego que se juega con la palabra "muerte", el juego que todos conocemos y entendemos. 6 Aquí, y anteriormente en esta conferencia, parece que Wittgenstein está cuestionando si podemos hablar de comprender una palabra o una oración cuando separamos la supuesta comprensión de las técnicas familiares de nuestro lenguaje.

No creo que las "Conferencias sobre la creencia religiosa" ayuden a resolver la cuestión acerca de si Wittgenstein rechaza la tesis malcolmiana del lenguaje, hasta dónde lo hace o en qué tipos de contextos. Las conferencias no son fáciles de interpretar y tratan con casos de lenguaje religioso, que muy bien podría pensarse que difieren significativamente de los tipos de casos en cuestión entre Rorty y Putnam. Esto es, incluso suponiendo que las "Conferencias sobre la creencia religiosa" han de leerse como Putnam lo hace, ellas, a lo más, establecen que entonces Wittgenstein no identificó simplemente diferencia en significado con diferencia en uso en todos los casos. Aun sería posible que hubiera querido hacer tal identificación en una amplia gama de casos. En su examen de Wittgenstein con respecto a la creencia religiosa, Putnam señala (p. 63) la conexión entre su lectura de las conferencias y las Investigaciones filosóficas, $\S 43$, en donde Wittgenstein dice que para una amplia clase de casos -aun cuando no para todos - en los que empleamos la palabra "significado", ésta puede definirse así: el significado de una palabra es su uso en el lenguaje. Sea que el uso en religión proporcione o no algunas de las excepciones que Wittgenstein tenía en mente, aún habría una cuestión acerca de casos de cambios en las técnicas de uso de palabras como "oro", "agua", "qué edad tiene

6 Cyril Barrett (comp.), Lectures and Conversations on Aesthetics, Psychology and Religious Belief, Oxford, 1966, pp. 68-69. 
esto" y demás; ise pretende que estos casos se incluyan en la amplia clase de casos en la que el significado puede explicarse como uso en el lenguaje? ¿Fue Wittgenstein un wittgensteiniano fatigado con respecto a esos casos?

\section{IV}

Quiero considerar, ahora, un Wittgenstein ligeramente anterior, el Wittgenstein de 1935 . En una conferencia que parece tener un carácter muy verificacionista, Wittgenstein considera este caso:

Puedo tener dos sillas que se ven exactamente iguales, quitarlas de tu vista, luego devolverlas y decir, apuntando a una de ellas, "¿Es ésta la silla en la que te sentaste?" En estas circunstancias no habría respuesta a esta pregunta, no tendría sentido. ${ }^{7}$

Wittgenstein nos invita a comparar ese caso con el de dos ríos que fluyen el uno en el otro. ¿Cuál río es el que prosigue el curso?

Si un arroyo desemboca en el Danubio, estaríamos inclinados a decir que es el Danubio el que prosigue y no el arroyo. Pero supóngase que dos ríos se juntan y continúan con un nuevo nombre; entonces podemos decir, idos han desaparecido y uno no tiene origen! Se puede imaginar que, en tales casos, habría gente que diría, "Bueno, o bien es el mismo río o no lo es, aun cuando no podamos descubrir eso". Esto sería absurdo.

Lo que importa de la comparación es que en el caso de las sillas, como en el caso de los ríos, si no hay ningún criterio para tener el mismo tal y cual, no tiene sentido la pregunta acerca de si lo tenemos. La comparación puede parecerle a uno no convincente en lo absoluto. Considérese una objeción (de A.D. Woozley) ${ }^{8}$ a la observación de Wittgenstein con respecto a la silla:

Es ridículo decir que, puesto que no tenemos forma de determinar si ésta es la misma silla, no tiene sentido preguntar si lo es. Pues podemos intentar encontrar una manera de determinarlo (p. ej., entrenando perros capaces de olfatear cuál es la silla en la que alguien se sentó o creando técnicas para el examen microscópico de la tapicería). Entendemos perfectamente bien de qué estamos intentando encontrar una forma de determinar; de otra manera, no podríamos llevar a cabo estos intentos de crear técnicas para descubrir cuál fue la silla en la que alguien se sentó. Es precisamente nuestra comprensión de la pregunta "¿En qué silla te sentaste?" la que nos guía en estos intentos. Así que es absurdo decir que la pregunta no tiene sentido.

7 Conferencia del 18 de noviembre de 1935. Todas las referencias a esta conferencia son a las notas de Margaret Macdonald (manuscritas), incluidas en el apéndice de este escrito.

8 La objeción se expresó en una conversación. Yo formulé la objeción. 
Creo que no es defendible la observación de Wittgenstein acerca de la silla. ${ }^{9}$ El uso que quiero hacer de ella es que conduzca a una consideración de un elemento del pensamiento de Wittgenstein que, en un sentido, es verificacionista (es preciso aclarar en qué sentido exactamente). Tendemos a pensar que el verificacionismo es lo que sostuvieron los positivistas lógicos y, así, la idea de que hay un elemento verificacionista en Wittgenstein parece como la idea de que sus tesis pueden, en alguna medida, identificarse con las de ellos. No es esto lo que sostengo y, quizás, es mejor hablar de un elemento 'verificacionista' en su pensamiento. Ciertamente hay similitudes entre algunas de las observaciones de Wittgenstein durante la década de 1930 y expresiones familiares, de los positivistas lógicos, acerca de sus tesis. Incluso si tan sólo consideramos esas observaciones de Wittgenstein, hay diferencias importantes tanto en las ideas expresadas como en las metas filosóficas más amplias. Aún más importante es que necesitamos distinguir entre esas ideas 'verificacionistas', como podríamos decir, en los escritos de Wittgenstein de ese periodo y alguna otra cosa, que también podría considerarse como una especie de 'elemento verificacionista' en su pensamiento. Espero aclarar lo que sea ese algo más; eso parecería que nos en puja hacia o dentro de alguna forma familiar de verificacionismo o de antirrealismo, pero no debe considerarse que lo hace. Así que estaré intentando mostrar lo que pueda ser un 'elemento verificacionista' en el pensamiento filosófico, que no es identificable ni con el verificacionismo de los positivistas ni con el 'verificacionismo' de observaciones como las referentes a la silla.

En la sección $\mathrm{V}$ considero una réplica, a disposición de Wittgenstein, a la objeción de Woozley. Por una réplica no quiero decir (no significo) una defensa de la observación original acerca de la silla, sino una respuesta, apelando a cosas que Wittgenstein dice en otros lugares, a las ideas expresadas en la objeción de Woozley.

\section{V}

Supóngase que Wittgenstein nos pide que consideremos dos oraciones:

1) "Me pregunto si ésta es la misma silla en la que te sentaste ayer". (Nadie conoce ninguna manera de distinguirla de la silla similar que está junto a ella.)

2) "Me pregunto si Aníbal estornudó seis veces mientras cruzaba los Alpes". (No tengo ninguna idea de cómo habría que hacer para determinar esto.)

9 Cfr. los comentarios de Elizabeth Anscombe acerca de una expresión relacionada de verificacionismo en Wittgenstein, en "Hume and Julius Caesar", en From Parmenides to Wittgenstein, Minneapolis, 1981, p. 89. 
Como respuesta a la propuesta de Woozley de que la pregunta acerca de la silla debe de tener sentido, porque nuestra comprensión de ella guía nuestro intento de encontrar una técnica para responderla, Wittgenstein podría decir que el mismo hecho de que nosotros si apelamos a tales formas, como las mencionadas (perros y técnicas microscópicas), de buscar una respuesta es lo que le da sentido a la pregunta. Es precisamente debido a que la pregunta acerca de Aníbal no está localizada dentro de nuestras actividades de buscarmaneras-de-establecer-cosas por lo que es diferente de la pregunta acerca de la silla. La imaginaria réplica wittgensteiniana continúa: no debemos llegar a decir "Y, por lo tanto, la pregunta acerca de Aníbal carece de significado", como si ésa fuese una nueva propuesta, una conclusión que hubiera que extraerse. Sucede, más bien, que las dos preguntas son diferentes en el aspecto que acabamos de señalar y ése es un aspecto al que quizás no le prestamos la atención suficiente. Nosotros queremos extraer una conclusión acerca de la significatividad después de tener claridad acerca de la diferencia en uso. Pero, si decimos que la primera pregunta tiene sentido y no lo tiene la segunda, esto tan sólo pone de manifiesto la diferencia.

No es esencial para esta réplica que digamos que la segunda oración no tiene sentido. Aquí está otra manera de formular la réplica (basada en material que se encuentra en la serie de conferencias de 1935 citada en la sección IV).

$\mathrm{Si}$ alguien dice que podríamos preguntarnos si Aníbal estornudó exactamente seis veces mientras cruzaba los Alpes, en lo que consiste tal pregunta es en decir, "Me pregunto si Aníbal estornudó exactamente seis veces mientras cruzaba los Alpes" y, quizás, también en estar en cierto estado mental; mientras que si alguien dice, "Me pregunto si ésta es la silla en la que te sentaste ayer", preguntarse, en este caso, no consiste sólo en un estado mental y en decir "Me pregunto...", etc. Yo podría entrar en contacto con un entrenador de perros, especializado en el uso de perros para investigaciones forenses. Entonces, nuestra plática acerca de en cuál silla te sentaste, está conectada con prácticas en las que se acepta la discriminación olfativa de perros para mostrar que el objeto $A$ y no el objeto $B$ es el que fue tocado por alguna persona o animal. Sea que encuentre o no una forma de determinar lo que quiero, en este caso hago mucho más que decir "Me pregunto".

\section{VI}

Permítaseme desarrollar más esta respuesta. ¿Qué implicaciones tiene para la pregunta acerca de si todo cambio en nuestras técnicas de investigación, toda nueva prueba para detectar la presencia de algo, tiene como resultado un cambio en el significado de nuestras palabras? Putnam arguye que tales cambios en las pruebas y en las técnicas de investigación no nos parece que cambien el significado de nuestras palabras. Si creamos una nueva prue- 
ba química para determinar si algo es agua, aún consideramos que queremos decir (significamos) lo mismo que antes mediante la oración "La materia de este vaso es agua" (NTO, p. 3).

No es preciso que la réplica wittgensteiniana que imaginé entre en conflicto con esa fenomenología, con lo que estamos inclinados a decir. Pero hemos de notar que difieren significativamente entre sí los casos en los que podemos estar inclinados a decir que el sentido de alguna oración no ha cambiado. Estaremos naturalmente inclinados a decir que el sentido no cambia cuando seguimos aplicando nuestras palabras con base en las mismas técnicas que hemos estado usando; pero, en ocasiones, podemos estar inclinados a decir que el sentido no ha cambiado aun cuando ahora estemos aplicando términos con base en las técnicas recientemente creadas. La atención a la fenomenología, a lo que estamos inclinados a decir, puede alejar nuestra atención de tales diferencias entre los casos. Éste no es un argumento de que cuando quiera que inventamos una nueva prueba, el significado si cambia. La pretensión filosófica de llamar la atención sobre la coexistencia de la inclinación fenomenológica de decir "ningún cambio en el sentido" en algunos casos con un cambio en cómo se aplican las palabras y, en otros, sin ningún cambio así, es dejar de preguntarnos si el sentido ha cambiado o no. Di lo que quieras, puede ser que no quieras seguir diciendo que el sentido no ha cambiado cuando cambian las técnicas de investigación. De hecho, creo que uno muy bien puede querer seguir diciendo (en muchos de estos casos) que el sentido no ha cambiado, por razones que expondré.

Primero tenemos que ver un asunto diferente, esto es, la inadecuación de la réplica que imaginé que daba Wittgenstein. El problema con ella no es tanto lo que dice como lo que no dice. No aclara qué es lo que en el pensamiento de Wittgenstein lleva exactamente a esas tesis que Putnam considera como pseudowittgensteinismo fatigado. ¿Qué razones tuvo Wittgenstein para decir, en muchos contextos y a lo largo de muchos años, cosas tales como que el sentido depende de los métodos de investigación y que en donde no tenemos ninguna idea de cómo conduciríamos una investigación, muy bien podemos decir las palabras "Me pregunto si $p$ ", pero la cuestión acerca de si es el caso que $p$ es absurda o vacía? Y la réplica no apoya bastante las razones -que también surgen en los escritos de Wittgenstein- para no decir que el sentido depende de los métodos de investigación.

Estos problemas le surgen a Wittgenstein en una diversidad de formas. Las cosas acerca de las que nos preguntamos pueden ser empíricas, como si la silla en la que ayer te sentaste fue aquélla o esta otra que es similar. $O$ bien, pueden ser matemáticas, como, antes de que hubiera una prueba de que no existía un número primo máximo, podríamos habernos preguntado cuántos números primos había. Hoy podemos preguntarnos si todo número par es la suma de dos primos. Las tensiones dentro del pensamiento de Wittgenstein 
acerca de los casos matemáticos, son similares a las que tiene acerca de los casos empíricos (como lo aclara el epígrafe de este artículo). En la sección VII considero los casos matemáticos y arguyo, además, que mi réplica imaginada de Wittgenstein a Woozley no va suficientemente lejos.

\section{VII}

Wittgenstein dijo repetidas veces que el sentido de lo que se prueba en matemáticas lo da la prueba. Esto, como él lo reconoció, tiene una consecuencia aparentemente paradójica. Si pregunto, antes de que haya una prueba, si todos los números pares son la suma de dos primos, entonces, cuando se dé la prueba, lo que ésta prueba no es que sea correcta cierta respuesta a mi pregunta original. Esto es, cuando (antes de tener una prueba) dije "Me pregunto si $p$ ", mi oración " $p$ " no significa lo mismo que la oración " $p$ " al final de la prueba. iHay inconmensurabilidad para ti! Esta tesis se enuncia sin reservas al principio de los años treinta, ${ }^{10}$ pero continúa siendo la tesis de Wittgenstein mucho después de eso.

Lo que hay que decir del lado opuesto, lo presenta claramente Wittgenstein en un estudio del último teorema de Fermat: ${ }^{11}$

Ahora bien, ino es absurdo decir que uno no entiende el sentido del último teorema de Fermat? - Bueno, se podría replicar, los matemáticos no están completamente en blanco e inermes cuando se enfrentan a esta proposición. Después de todo, ellos intentan ciertos métodos de probarla y, en la medida en que prueban métodos, en esa medida entienden la proposición.- Pero, ies eso correcto? :No simplemente la entienden tan completamente como le sea a uno posible entenderla?

También vale la pena citar aquí algunas otras observaciones del mismo contexto:

Pero si he de saber lo que dice una proposición como el último teorema de Fermat, ino debo saber cuál es el criterio para que sea verdadera la proposición? Y, ciertamente, tengo conocimiento de criterios de verdad de proposiciones simila$r e s$, pero no de ninguno de esta proposición.

'Comprensión', iun concepto vago!...

"Voy a mostrarte cómo hay infinitamente muchos números primos" presupone una condición en que la proposición de que hay infinitamente muchos números primos no tenía, para la otra persona, ningún significado o sólo el más vago. Para ella podría haber sido meramente un chiste o una paradoja.

10 Véase, p. ej., Philosophical Remarks, pp. 188-189.

11 En la sección VI de la edición de 1978 de Remarks on the Foundations of Mathematics. El pasaje (pp. 314-315) proviene de una época de entre 1941 a 1944. 
En esas observaciones podemos ver que los problemas acerca de comprender una proposición matemática antes de que tengamos una prueba, son muy similares a los problemas acerca de hablar de la edad de los huesos en Whoozie, antes de que tengamos cualquier método para fechar los huesos. ${ }^{12}$ El pasaje también sugiere que la réplica de Wittgenstein que propuse para el argumento de Woozley no va lo bastante lejos. Preguntar si los matemáticos no entienden la proposición de Fermat tan completamente como sea posible para uno entenderla (esto es, tan completamente como lo harían si descubriesen una prueba), es poner en duda el tipo de enfoque según el cual a lo que equivale 'comprenderla' puede verse en lo que hacen los matemáticos y que lo que ahora hacen es intentar varios métodos de probarla. Esto es diferente de lo que harán con ella una vez que haya habido avances en matemáticas, quizás incluyendo cambios imprevisibles en las que se reconocen como técnicas de prueba, y ellos lleguen a tener lo que reconocen como una prueba.

(No puedo analizar aquí la cuestión acerca de si hemos de identificar cualquiera de las observaciones en el pasaje citado con un 'interlocutor' wittgensteiniano.)

\section{VIII}

¿Por qué ligó Wittgenstein el sentido de las cuestiones empíricas a métodos de descubrimiento y a pruebas el sentido de las proposiciones matemáticas? Sus razones están muy relacionadas a sus ideas acerca de la gramática. No me es necesario ni posible dar una versión completa de cómo él usa ese término; una manera como lo usa es al explorar la importancia de las desviaciones de nuestras formas de usar las palabras. Supóngase que hubiese gente cuyo conjunto de prácticas de fechar las cosas se traslapase con la nuestra, pero de algunas maneras difiriese. ¿Estarían dando erróneamente las fechas de las cosas o no las estarían fechando, precisamente, sino (digamos) tiempándolas? La diferencia entre ellos y nosotros está en la gramática de la expresión que se usa; esto es, "gramática" es el término de Wittgenstein para caracterizar los rasgos de las maneras de usar una expresión que tiene la gente, incluyendo sus métodos de investigación. Para la relación entre métodos de verificación y gramática,

12 Una observación importante de Wittgenstein se refiere a la analogía entre "proposiciones matemáticas" y las otras cosas que denominamos proposiciones; la analogía depende de la analogía entre verificación (en el caso de una proposición empírica) y el método de comprobar la verdad (en el caso de la proposición matemática). Véase la Philosophical Grammar, p. 366. La implicación es que hay, entonces, una analogía entre los problemas acerca de las proposiciones empíricas sin método de verificación y los problemas acerca de las proposiciones matemáticas no probadas y una analogía entre el efecto de un nuevo método de verificación sobre el significado de una proposición empírica y el efecto de un nuevo método de prueba de una proposición matemática. 
véanse las Investigaciones filosóficas, $\S 353$; la especificación de cómo verificamos una proposición es "una contribución a la gramática de la proposición". Wittgenstein también trata la prueba de una proposición matemática como una contribución a su gramática. Piénsese en cómo la prueba de que no hay ningún número primo máximo nos proporciona un método, que antes no teníamos, para rechazar cualquier aseveración de que tal y cual es el primo máximo y, de esa manera, cambia las formas disponibles de hablar. Entonces, las pruebas y los nuevos métodos de investigación empírica, al cambiar las formas establecidas o al poner en cuestión lo que es el caso, son contribuciones a las actividades de usar el lenguaje (esto es) pertenecen a la gramática.

En las conferencias de 1935 que cité antes, Wittgenstein analizó la 'arbitrariedad de la gramática', aun cuando señala que la etiqueta es engañosa. Él arguye que si ordenamos la gramática de manera diferente, no erraremos con respecto a la naturaleza de aquello de lo que hablamos; más bien, estaremos hablando de algo diferente. ${ }^{13}$ Cómo ordenemos la gramática puede ser prácticamente conveniente o inconveniente; pero no es reponsable (porque no es separable) de la naturaleza de las cosas acerca de las que hablamos. En el caso de las cuestiones empíricas, a la gramática de una cuestión le pertenece el qué técnicas hay para resolver tales asuntos. Así, en un sentido importante, qué es lo que sucede con aquello acerca de lo que preguntamos (la 'edad de los huesos de Whoozie', p. ej.), depende de técnicas de investigación, de la manera como resolvemos tales cuestiones.

Ahora podemos ver que el argumento de Woozley toca el núcleo de la cuestión. Woozley dijo que cuando tenemos una cuestión, pero no tenemos manera de responderla, lo que guía nuestra búsqueda por un método y nuestro juicio de que hemos encontrado un método apropiado, es nuestra comprensión de la cuestión, nuestra captación de qué es lo que estamos intentando descubrir. Así, éste es un argumento de que lo que estamos intentando descubrir hace apropiados ciertos métodos y otros no. $\mathrm{Y}$, puesto que los métodos de investigación pertenecen a la gramática, el argumento de Woozley es que nuestra captación de qué es lo que estamos intentando encontrar nos guía adecuadamente para fijar la gramática. Ése, entonces, es un claro rechazo de la idea de que la gramática fija aquello de lo que estamos hablando.

(La relación entre el argumento de Woozley y las ideas fundamentales de Wittgenstein puede verse también en el escrito "Riddles and Anselm's Riddle”, de Roger White. ${ }^{14}$ White analiza las consecuencias de la tesis de Wittgenstein de que es la prueba de una proposición matemática la que nos muestra el significado de la proposición probada. En un escrito anterior a la

13 Cfr. Zettel, § 320; Investigaciones filosóficas, §§ 371 y 373.

14 En los Proceedings of the Aristotelian Society, supl. 51, 1977, pp. 169-186; véanse especialmente pp. 171-173. 
publicación en inglés de los pasajes que cité de las Remarks on the Foundations of Mathematics, él arguye, con mayor detalle, precisamente lo que se arguye en el primer pasaje citado, esto es, que entendemos perfectamente bien cl último teorema de Fermat. Luego da un argumento paralelo al de Woozley; dice que es "difícil dar una caracterización de los siglos de investigación dedicados al intento de probar o de refutar este Teorema, sobre el supuesto de que los matemáticos estaban explorando una tesis cuyo sentido no entendían perfectamente bien". No debemos pensar que hay alguna duda filosófica acerca de si ahora podemos creer el teorema de Fermat.)

\section{IX}

¿En dónde estamos? La idea de Putnam era que si Leibniz había pensado que los huesos de Whoozie tenían un millón de años, él habría acertado y él también arguyó que se necesita ser un pseudowittgensteiniano burdo para negarlo. Yo he estado intentando mostrar el tipo de consideraciones que llevaron a Wittgenstein a ligar el significado a los métodos de investigación. Ciertamente, puede parecer que estas consideraciones apoyan las lecturas antirrealistas de Wittgenstein más radicales. Tengo en mente la lectura que hace Crispin Wright de Wittgenstein y su aseveración de que los argumentos de Wittgenstein minan la idea que tenemos de hechos independientes de nuestras investigaciones reales. Conforme a una lectura malcolmiana, lo que se quiere decir con (lo que significa) "Estos huesos tienen al menos un millón de años" se establece sólo cuando tenemos algunos medios para establecer la edad de los huesos. La oración no tiene significado hasta entonces. Conforme a una lectura antirrealista, más radical, las condiciones de verdad de "Estos huesos tienen al menos un millón de años" no se establecen ni siquiera cuando tenemos las técnicas para investigar tales asuntos, porque no se establece aún cómo hemos de aplicar esas técnicas al caso particular de estos huesos. Lo que cuenta como aplicar esas técnicas de la misma manera como lo hemos estado haciendo, depende de qué es lo que aceptamos, cuando la investigación se lleva a cabo, como aplicarlas de la misma manera. Hasta que realmente no hayamos llevado a cabo la investigación, permanece indeterminado qué 'aspectos del mundo' cuentan para mostrar que es verdadera o falsa nuestra oración acerca de los huesos. ${ }^{15}$

15 Wittgenstein on the Foundations of Mathematics, Londres, 1980, p. 196; también el cap. XI. No analizaré aquí la lectura de Wright. Cualquier crítica de ella como lectura ha de tomar en serio el soporte textual que se le pueda dar. No se puede argüir en contra de ella que la lectura pasa por alto la importancia de la comprensión, por parte de Wittgenstein, de la relación interna entre una regla y su aplicación a un caso particular. Wittgenstein mismo rechaza, de manera decisiva, el intento filosófico de, en tales casos, apelar a relaciones internas. Él arguye que luego que hemos introducido el uso de "rojo", mediante una definición ostensiva, podríamos seguirla usando, no (como lo hacemos) para muchos matices diferentes de rojo, sino para Do sostenido 
Así pues, ¿cuáles son las consecuencias, para la mismidad de las creencias en tiempos diferentes, de esta lectura antirrealista? Si en cualquier momento, anterior al fechado real de los huesos, dices "Creo que los huesos tienen un millón de años”, parece que a lo más que podría equivaler tu creencia es a la creencia de que cuando se fije lo que cuenta como hacer verdadera la oración 'Los huesos tienen un millón de años', resultará que la oración expresa algo verdadero. Pero no es eso lo que creemos posteriormente. Aquí hemos de comparar las propias observaciones de Wittgenstein acerca de tener la corazonada de que es correcta la conjetura de Goldbach. Él dice que, como podemos extender las matemáticas de tal manera que la conjetura resulte ser verdadera o extender las matemáticas de tal manera que no lo haga, tener una corazonada de que es correcta la conjetura de Goldbach es tener una corazonada de que las matemáticas se extenderán de tal manera que se diga de la conjetura que es acertada. ${ }^{16}$

He argüido que el 'verificacionismo' aparente de Wittgenstein no es una cuestión ni de malas lecturas impuestas sobre los textos, ni de una tesis que él mantuvo por unos cuantos años y abandonó como una especie de tentación filosófica de la que se había curado. Un elemento 'verificacionista' dentro de su pensamiento está ligado a sus ideas acerca de la gramática; la gramática en tanto que muestra de qué estamos hablando. ${ }^{17}$

Putnam acierta al decir que a Wittgenstein no se le lee adecuadamente como un verificacionista; pero (creo que) él no ve hasta dónde el 'verificacionismo'

y el olor de lavanda. Si lo hiciésemos, entonces diríamos que ellos están relacionados, con las cosas anteriores que llamábamos rojas, por la relación interna de 'ser similar en color'. Decir que llamamos rojas a la sangre y a las fresas, tras haber dado la definición ostensiva, porque hay una relación interna entre las cosas que llamamos rojas es, dice él, dar una regla de gramática para "rojo". Lo que Wittgenstein aclara en este examen (en una conferencia del 21 de enero de 1936, parte de la cual está incluida en este escrito) es la imposibilidad de replicar a una lectura como la de Wright mediante los argumentos de Baker y Haker en Scepticism, Rules and Language; él trata, especificamente, con la propuesta central que presentan en la p. 96.

16 Lectures on the Foundations of Mathematics, p. 137. Véase también, Philosophical Grammar, p. 361 .

17 También está conectado, en formas que no analizaré, con su estudio de lo que está comprendido en seguir una regla. Mi lectura de Wittgenstein, con respecto a la cuestión del verificacionismo, difiere no sólo de la de Putnam, sino también de la de Peter Winch en Simone Weil: "The Just Balance". Winch arguye que, aun cuando a Wittgenstein le interesaban los problemas que les preocupaban a los positivistas lógicos, no hay ninguna 'afinidad cercana' entre su punto de vista y el de ellos. Pero 'afinidad cercana' y mera prẹocupación con los mismos problemas no son las únicas posibilidades. Tal como yo leí las conferencias de Wittgenstein de 1935, él pensó que era útil (en conexión con los problemas acerca de la experiencia personal y de la mismidad de las imágenes residuales) decir que no tenía sentido una probable oración empírica que no pudiese verificarse. Yo estaría de acuerdo con Winch en que esto no hay que leerlo como un verificacionismo del tipo que mantuvieron los positivistas. Pero creo que no es preciso que haya nada engañoso en señalarla como una expresión de un elemento verificacionista en el enfoque de Wittgenstein a diversos problemas. 
es algo que está dentro del pensamiento de Wittgenstein. Ello no es para él una mera tentación filosófica, aun cuando lo sean algunos modos de expresarla. Y, así (dentro del contexto de la filosofía de Wittgenstein), es compleja la réplica a la voz verificacionista y no es meramente una corrección de expresiones del verificacionismo confundidas filosóficamente (como Putnam parece sugerirlo en "Wittgenstein on Religious Belief"). ${ }^{18}$ Exploro más estos asuntos en las secciones X-XII en este trabajo, pero primero deseo hacer notar la relación entre mi lectura de Wittgenstein y dos observaciones suyas ya citadas: el epígrafe a este escrito y $\S \mathbf{3 5 3}$ de las Investigaciones. Las dos observaciones presentan, de maneras diferentes, la importancia del lazo entre lo que se quiere decir (se significa) con una oración y lo que justifica aseverarla y la importancia de no tratar ese lazo como la base de una identificación reductiva del significado con método de verificación o con condiciones de aseverabilidad. ${ }^{19}$

\section{$\mathrm{X}$}

Aquí será útil considerar otro ejemplo, que se asemeja a los que examinamos anteriormente. Quizás tenemos un método para determinar si los perros sueñan o no (he leído que lo tenemos); pero, aun si lo tenemos, no es un método que nos permita determinar el contenido de sus sueños. Sin embargo, ino es verdad que parece posible que hayan de soñar con perseguir conejos o incluso con que son perseguidos por conejos gigantes? Si en una historia, contada desde el punto de vista de un perro, se nos cuentan tales sueños, ciertamente no pensaríamos que carecen de significado las oraciones que estamos leyendo. Ahora, considérese esta oración, "Si alguien cree que su perro está soñando con perseguir ardillas, entonces o bien tiene razón o está equivocado, sea o no que tengamos una manera de determinarlo."

¿Cómo podría Wittgenstein responder a alguien que dijese eso ${ }^{20}$ Él podría decir que cuando hablamos en esa forma "o bien... o", parece como si estuviéramos aseverando que hay dos alternativas, esto es, la persona que cree que los perros sueñan acerca de ardillas cree certera o cree erróneamente. Pero lo que estamos haciendo es insistir en mantener un uso particular de "cree". Si vamos a decir de esta persona "Ella cree esto acerca de los perros", esa forma de hablar acarrea (nosotros deseamos acarrear esto con ella) el hablar de creer

18 Véase, en pp. 63-64, el pasaje estudiado en la sección III de este trabajo.

19 Estoy en deuda con James Conant por las sugerencias acerca de mis argumentos aquí. Él también subrayó la importancia de la primera oración de § 353 , que no he citado anteriormente, "La cuestión acerca del método y de la posibilidad de la verificación de una proposición, es sólo una forma particular de la cuestión 'QQué quieres decir (significas) con eso?”. Es una forma de esa pregunta, pero sólo una forma particular.

20 La respuesta que imagino se basa en el estudio que hizo Wittgenstein del experimento Michelson-Morley en la conferencia del 18 de noviembre de 1935, incluida en el apéndice. 
certera o erróneamente. Pero no estamos rebasando el hecho de que queremos usar "cree que" en este contexto.

(Hay otras formas de usar "cree que". Al estudiar asuntos relacionados, Rorty usa el ejemplo "Teseo fue el hijo de Poseidón, no de Zeus". Si decimos de alguien que creyó eso, ese uso de "creer" no lleva consigo "él creyó acertadamente o él creyó errróneamente".) $)^{21}$

Estamos dispuestos a decir de alguien, él cree que los perros sueñan ese tipo de cosas. Usamos "cree" en ese tipo de contexto, aun cuando no tenemos forma de investigar la cuestión; si él dice "Yo creo etc.", nosotros no diríamos que él tan sólo ha emitido una oración que, quizás, algún día se podrá usar para expresar una creencia, ni pensamos que la persona crea tan sólo que cuando se haya fijado qué 'aspectos del mundo' establecen la verdad o la falsedad de la oración, ésta resultará ser una oración verdadera. Asimismo, y de modo similar, usamos "cree que" de esta manera, esto es, si la narración de Putnam fuese verdadera, entonces alguien, en el siglo XVII, creyó que los huesos que se encontraron en Whoozie tenían un millón de años. Esto es, estamos dispuestos a hablar acerca de gente, cuya vida difiere de la nuestra en tanto que carece de muchas técnicas de investigación que nos son importantes, como si creyera lo que nosotros. Y cuando, en filosofia, estudiamos esta tendencia, no vamos más allá de ella hasta algo que la apoye, aun cuando parezca que lo hacemos.

Esta tendencia a adscribir las mismas creencias que las nuestras a gente cuya vida, con las palabras que consideramos que expresan esas creencias, es muy diferente de la nuestra, es un fenómeno humano sorprendente y notable. Es uno de los rasgos característicos de nuestra relación con el pensamiento de otra gente.

Podemos conectarlo con el caso de la traducción. Cuando Putnam estudia la versión que da Malcolm de Wittgenstein, objeta que la tesis que Malcolm le adscribe a Wittgenstein nos obliga a decir que la palabra "agua", usada en una novela o en una carta de 1700 , no significa lo que la palabra significa hoy, porque han cambiado nuestras técnicas para determinar si algo es agua. $\mathrm{Y}$, así, se seguiría que no habríamos de traducir la palabra "water" usada en 1700 por "water" del inglés contemporáneo. En contra de esto, Putnam argumenta que Wittgenstein, de manera muy sensata, concedería que hubiese mismidad de significado a pesar de las diferencias en los métodos de verificación y, así, no se comprometería con la imposibilidad de tales traducciones. Wittgenstein, tal como yo lo leo, podría llamar nuestra atención a este fenómeno, a que simplemente vamos adelante y tomamos, como nuestra, la palabra "water" de esa gente, que simplemente estamos tentados a 'traducir' su palabra "water"

21 Para un análisis de estas cuestiones, véase John McDowell, "On the Sense and Reference of a Proper Name", Mind, no. 86, 1977, pp. 159-185, especialmente, § 8 . 
por "water". Esto no lo hace correcto el que el significado de una palabra sea independiente de técnicas de investigación. Más bien, la vida del siglo XVII, con la palabra "water" es, de muchas formas, muy similar a la nuestra; en presencia de las muchas similitudes y las limitadas diferencias, lo que nosotros hacemos en la mayoría de los contextos en los que queremos hablar acerca de sus pensamientos, es conectarlos con los nuestros, tratando sus palabras exactamente de la misma manera como tratamos la palabra en boca de uno de nuestros contemporáneos.

Cuando Putnam dijo que si una persona del siglo XVII hubiese considerado la idea de que los huesos de Whoozie tuviesen un millón de años, ella estaría en lo cierto; añade que ése es un cuadro que tenemos, un cuadro "que tiene tanto peso en nuestras vidas como la idea de que hay gente ahí fuera, en el pasado y en otras culturas en el presente, con la que podemos comunicarnos". Tales cuadros son intrínsecos a las prácticas que informan y apoyan. Aquí la sugerencia es que vemos a los otros como estando en el mismo espacio mental que el nuestro, capaces de hablar de las mismas cosas, capaces de decir y de, aproximadamente, significar lo mismo que nosotros. Ésta es una idea de lo que es posible de la relación entre su pensamiento y el nuestro. Pero, tal idea capoya e informa nuestros juicios de lo que realmente sucede, nuestra práctica? Aquí, la nuestra es la práctica compleja de comunicarnos con la gente, una práctica que incluye la adscripción de creencias en una gran variedad de circunstancias. La oración de Putnam "si una persona del siglo XVII hubiese... considerado la idea de que los restos del esqueleto hallados en Whoozie tuviesen un millón de años, esa persona estaría en lo cierto", no proporciona tanto un cuadro en apoyo de nuestra práctica, sino una muestra de nuestra práctica. Nosotros no pasamos de nuestra práctica a una idea o un cuadro de las relaciones y el lenguaje humanos que forman un tipo importante de apoyo para ella.

Hay un problema similar acerca del contraste que establece Putnam entre las tesis reales de Wittgenstein y la lectura que hace Malcolm de Wittgenstein. Putnam lee a Wittgenstein como si éste aceptara que el significado puede permanecer sin cambio cuando cambian las técnicas de investigación. ¿De qué sirve tal tesis? ¿Para qué la podríamos querer? La necesidad aparente de mantener que el significado permanece sin cambio en tales circunstancias, surge porque parece que pueden ser correctas nuestras adscripciones de creencias a la gente en el pasado, acerca del agua, de la edad de los huesos o de lo que sea, sólo si sus oraciones pueden significar lo que significan las nuestras y el verificacionista ha cuestionado eso. Pero nuestra respuesta al desafío no ha de ser la de entrar en un debate con el verificacionista acerca de cuándo pueden ser iguales los significados o acerca de cuándo pueden las oraciones de la gente referirse a las mismas cosas. Putnam sostiene que hay ideas importantes acerca de la mismidad del significado, ideas que Wittgenstein no 
cuestiona, que apoyan nuestras prácticas. En contra de esto, estoy arguyendo y presentándolo como una tesis de Wittgenstein, que estas prácticas no están apoyadas por tales creencias o cuadros. ${ }^{22}$ (Aquí no estoy formulando ninguna aseveración general acerca de la importancia que los cuadros puedan tener en conexión con nuestras maneras de usar las palabras. Esto es, no estoy negando la importancia de casos en los que "todo el peso pueda estar en el cuadro".)

\section{$\mathrm{XI}$}

He aquí una observación pertinente de Wittgenstein:

el terreno continúa dándonos la imagen ilusoria de una mayor profundidad y, cuando intentamos alcanzarla, seguimos encontrándonos en el viejo nivel. ${ }^{23}$

La imagen ilusoria (en nuestro caso presente) es la de algo que yace tras la práctica de decir tales cosas como que Leibniz creyó acerca de los huesos lo que ahora sabemos que es así. Estamos dispuestos a adscribirle nuestras creencias, dispuestos a tratar la oración en su boca como acerca de la edad de los buesos, tal como usamos nuestras palabras, incluyendo "triángulo", al expresar las creencias de un niño de seis años, cuya vida con la palabra "triángulo" es muy diferente de la nuestra. Conforme a la tesis de Wittgenstein, son las pruebas geométricas las que determinan la gramática de la palabra "triángulo" y esa tesis parece implicar que una persona que usa la palabra, sin ninguna comprensión de esas pruebas, está usando una palabra con una gramática diferente, por tanto, no quiere decir lo mismo que nosotros y, por tanto, sus creencias acerca de lo que ella llama triángulos no son creencias acerca de triángulos en nuestro sentido. (Compárese la observación de Wittgenstein, citada antes, de que para la persona que aún no ha adquirido la prueba de que hay un número infinito de primos, la proposición que dice que los hay no tiene ningún significado o sólo uno muy vago. $\mathrm{Y}$ compárese, también, el estudio de Stanley Cavell de qué es, para tal y cual tipo de objeto, 'existir en el mundo de alguien'.) ${ }^{24}$ Aquí estoy llamando la atención sobre el hecho de que en nuestra práctica no nos negamos a tratar las creencias de un niño como creencias acerca de triángulos. Pero no quiero ir más allá del hecho de que, en nuestra práctica, le adscribimos creencias acerca de triángulos al niño, a la idea

22 Compárese la práctica de tomar algo de lo que se nos dice como si contradijese lo que nosotros hemos dicho. En esta práctica, hacemos que nuestras emisiones concuerden, hacemos que mantengan tales y cuales relaciones lógicas. La práctica es fundamental y no se apoya en ideas acerca de que la gente sea capaz de mantener creencias contradictorias o en cualesquiera otras ideas.

23 Remarks on the Foundations of Mathematics, p. 333.

24 "Excursus on Wittgenstein's Vision of Language", Claim of Reason, pp. 168-190, especialmente en pp. 172-173. 
de que lo que informa o apoya nuestra práctica es una idea del significado tan capaz de ser la misma, a pesar de diferencias en el dominio de la geometría o una idea del niño como alguien con quien podemos comunicarnos, alguien capaz de significar lo mismo que nosotros.

Lo que acabo de dar como una versión 'wittgensteiniana' puede parecer muy próxima a la tesis rortyana que Putnam objetaba, la tesis que decir que la oración del siglo XVII era verdadera entonces es simplemente alabarnos a nosotros mismos. Pues, según como nos he descrito, simplemente tomamos ciertas oraciones emitidas con aparente fuerza aseverativa o como conjeturas y las tratamos como expresiones de lo que ahora diríamos si emitiésemos esas oraciones. Putnam denominó la tesis rortyana una teoría emotiva de la verdad, porque la palabra "verdadero" se trata como un mero cumplido; pero, entonces, ¿qué estoy diciendo, si no es que alabamos a Leibniz por tratar su oración como si expresase nuestra creencia? ¿Qué estamos haciendo si no dando palmaditas a la gente por llegar a oraciones como las nuestras? Sugiero que estamos haciendo conexiones entre actividades de pensamiento y de habla que son diferentes de ciertas maneras. A esas diferencias les daríamos mucho o poco peso. Hay diversas formas posibles en las que podríamos configurar nuestro concepto de mismidad de pensamiento, mismidad de creencia. La forma que le damos, en nuestras adscripciones de creencia, es que nuestro pensamiento o creencia que es parte de una actividad que difiere de la nuestra en muchas de las técnicas disponibles, puede ser el mismo que el pensamiento o la creencia que es parte de nuestra vida con las palabras. Hay un gran significado humano en que de hecho hagamos, de esta manera, conexiones de pensamiento.

También en nuestra práctica estamos haciendo la noción de algo que la gente, en tiempos diferentes, con diferentes técnicas de investigación, puede creer, puede decirse que cree, en tanto que nosotros usamos la misma oración para enunciar nuestras creencias y expresar las de ellos. Hacemos la noción de algo con condiciones de verdad independientes de técnicas de investigación, en tanto que usamos la misma oración para enunciar nuestras creencias y expresar las de la gente que vivió hace cientos de años. Así que aquí estoy rechazando la idea de que la mismidad de condiciones de verdad haya de pensarse como si apoyase nuestra práctica. El cuadro de que la mismidad de condiciones de verdad apoya nuestras prácticas de traducir, es una elaboración filosófica de los hechos complejos de nuestra práctica real; su atractivo yace en que aparentemente va más allá de lo que hacemos.

$\mathrm{Al}$ argüir en contra de Rorty, Putnam apela a la diferencia entre una versión davidsoniana de la traducción y una versión quineana (NTO, pp. 6-7). Una versión davidsoniana, aplicada al caso actual, podría tener en ella la oración, "Los huesos de Whoozie tienen un millón de años" es verdadera en el español [inglés en el original] del siglo XVII si y sólo si los huesos de Whoozie 
tienen un millón de años. Si Rorty sigue a Davison aquí, debe, según arguye Putnam, distinguir este esquema del esquema quineano que simplemente concede que la oración del siglo XVII la 'traduzca' nuestra oración "Los huesos de Whoozie tienen un millón de años” y, así, Rorty debe conceder que la especificación de condiciones de verdad en el esquema davidsoniano tiene peso significativo. Pero el esquema davidsoniano puede bloquear nuestra visión de qué es anotar las traducciones que damos para nuestra comprensión de los lenguajes entre los que estamos traduciendo. Considérese el caso familiar de "La nieve es blanca" " "Schnee ist weiss". Existe la vida en la cual se usa la oración alemana y la vida en la que se usa "La nieve es blanca" y también hacemos conexiones entre la vida alemana y la vida española [inglesa, en el original]. Esto es, hay muchos actos, de diversos tipos, en lo cuales mostramos nuestra disposición de tratar esas vidas como reconociblemente similares, actos como hacer listas de vocabulario para que las aprendan los niños, actos como los de adscribirles a los alemanes creencias afines a las nuestras, etc. Las prácticas en las que forjamos tales conexiones (según arguyo) no se apoyan en cuadros de la relación entre entender y las condiciones de verdad. Más bien, hay ramas de la familia de los juegos de lenguaje de traducción que se prestan a la representación davidsoniana.

También es importante que deseemos llamar la atención a laṣ diferencias más bien que a las semejanzas entre la vida que tiene algún grupo de gente con alguna palabra o palabras y la vida que algún otro grupo de gente tiene con, por ejemplo, una palabra para el mismo lugar. Podemos querer insistir en decir que no hay traducción entre los dos grupos. Tal caso se presenta en la obra de Brian Friel, Translations (Londres, 1981); el nombre irlandés "Baile Beg" y el inglés "Ballybeg" pueden ser nombre del mismo lugar, pero los juegos de lenguaje en los que se usan tienen una similitud tan limitada, tan graves diferencias, que las oraciones que contienen las dos palabras pueden tratarse (como nos lo deja ver Friel) como inconmensurables. Y aquí se podría decir que los dos nombres, en un sentido, no son, después de todo, nombres del mismo lugar, porque el lugar Baile Beg no existe en el mundo de los soldados británicos (para usar la forma de hablar de Stanley Cavell, que cité). ${ }^{25} \mathrm{La}$ cuestión de la traducción es aquí política; concentrarnos en casos como " $\mathrm{La}$ nieve es blanca" o, incluso, "Estos huesos tienen un millón de años", desvía nuestra atención de los casos en los que razonablemente podemos negarnos a hacer, entre vidas humanas, esa unión que se hace al tratar nuestras palabras como si se adecuasen a las palabras de otros. La obra de Friel hace explícita la relación entre el fracaso de la conectividad humana y la ausencia de unión

25 Véase, también, el argumento de Alasdair MacIntyre acerca de tales parejas de nombres de lugares en "Relativism, Power and Philosophy", Proceedings and Addresses of the APA, no. 59, 1985, pp. 5-22, especialmente p. 7. 
de las palabras, como también hace explícita, y con gran efecto cómico, la relación entre la conectividad humana del campesino irlandés con el autor de las Geórgicas y la conexión entre el irlandés y el latín. Putnam dice que tenemos la idea de que hay gente ahí afuera, en el pasado y en otras culturas en el presente, con la que nos podemos comunicar. La obra de Friel presenta tal comunicación con gente en el pasado, pero también muestra cómo es que hay gente ahí afuera con la que no hay comunicación real; el lenguaje de un ejército de ocupación no es un medio de comunicación, sino de ocupación. ${ }^{26}$

Hablando de convicción matemática, Wittgenstein dijo que podría presentarse en la forma "Yo reconozco esto como análogo a aquello" y añadió que "reconocer" se usa ahí, no como en "Lo reconozco como Lewy", sino como en "Lo reconozco como superior a mí mismo". Es la indicación de que uno acepta una convención. ${ }^{27}$ Aquí estoy argüyendo que aceptar una traducción es algo similar; es un 'reconocimiento de esto como análogo a aquello' y el uso de "reconoce" es como el que se da en "Lo reconozco como superior a mí mismo". Entonces, lo que he sugerido acerca de la obra de Brian Friel es que puede llevarnos a decir, no reconoceré una oración acerca de Baile Beg como análoga a una oración acerca de Ballybeg. Si hay inconmensurabilidad entre los lenguajes, esto es cuestión de negarse a aceptar convenciones que permitan la traducción.

En "The Craving for Objectivity", Putnam subraya que lo que hace correcta una traducción depende del contexto y de nuestros intereses. ${ }^{28}$ Creo que mi tesis es diferente de la suya. Aun cuando, como Putnam, yo rechazaría la idea de inconmensurabilidad basada en que estamos prisioneros en nuestras propias formas de pensamiento o lenguaje, dejo espacio para la inconmensurabilidad basada en nuestro posible deseo de negarnos a 'reconocer esto como análogo a eso'. Esto no elimina la objetividad de nuestras prácticas de traducción, así como tampoco la propuesta de Wittgenstein elimina la objetividad de nuestras prácticas de prueba (pero ésta es otra historia y la analogía entre prueba y traducción no puede presionarse mucho).

\section{XII}

Si retrocedemos al siglo XVII, podemos imaginar que la historia de nuestra cultura se hubiera desarrollado de manera muy diferente a como lo hizo. En esta nueva narración, las ciencias no se desarrollan como de hecho lo hicieron. El trabajo científico se coarta, luego se suprime y se trata como inspirado por

26 Para un resumen de las controversias acerca de la relación entre política y lenguaje en la obra de Friel, véase Richard Kearney, Transitions: Narratives in Modem Irish Culture, Dublín, 1988, apéndice II del cap. 6, pp. 154-155.

27 Lectures on the Foundations of Mathematics, p. 63.

28 Realism with a Human Face, Cambridge (Mass.), 1990, p. 122. 
el diablo. Se descubren varios rollos antiguos y se consideran de inspiración divina. Se cree que contienen, de alguna manera críptica, las respuestas a las preguntas que nosotros podríamos decir que eran empíricas. En las universidades se desarrollan y se enseñan procedimientos para encontrar estas respuestas ocultas en los textos sagrados. Los textos se usan para fechar los sucesos; asignarle una fecha a un suceso pasado es asignarle una fecha de 0 a 6000 años atrás -ése es su sistema de datación. Usando los textos sagrados se determina que los huesos de Whoozie tienen 1200 años. ${ }^{29}$

La observación de Putnam acerca de nuestra habilidad para comunicarnos con gente en culturas diferentes de la nuestra, sugiere que él diría que la gente en la cultura que he descrito tiene creencias acerca de qué tan viejos son los huesos. Esto es, él aceptaría la forma como acabo de 'traducir' sus creencias cuando dije que ellos considerarían que los huesos tenían 1200 años. Y creo que diría que están equivocadas sus creencias acerca de la edad de los huesos. Pero aquí hemos de notar que dentro de su vida con el hablar acerca de la edad de las cosas, se trataría como una especie de chiste decir de algo que tiene un millón de años. En su gramática no hay lugar para la bipótesis de que los huesos tienen un millón de años; no hay ninguna movida así dentro de su juego. No estoy diciendo que su lenguaje sea inconmensurable con el nuestro; estoy concediendo que ciertamente podriamos 'traducir' sus oraciones a nuestro lenguaje y adscribirles creencias falsas acerca de la edad de los huesos. Pero hemos de notar que estamos haciendo esto a través de una gran diferencia en gramática. Su vida con el hablar cuál es la edad de las cosas es muy similar a la nuestra de algunas maneras y muy diferente en otras. Si alguien en esa cultura emitiese la oración, "Esos huesos tienen un millón de años", ciertamente podríamos decir, "Acertó con la edad de los huesos", pero el que digamos eso se acerca más a ser un cumplido para la oración, que tiene un lugar muy diferente en nuestra vida del que tiene en la de ellos. (Quiero decir (significo) que esto se acerca más a ser un cumplido para la oración que lo que sería decir lo mismo de Leibniz.)

Si decimos de alguien de otro tiempo o de otra cultura que al emitir la oración acertó en tal o cual cosa, qué tanto se acerque eso a ser tan sólo un cumplido referido a la oración, dependerá de qué tan alejada de nuestra cultura esté aquella cultura en su vida con esas palabras. En el caso de la especulación de Leibniz acerca de los huesos, pensamos en él como ya dentro de una cultura científica, una cultura en la que las teorías pueden ligarse unas a otras en el diseño de instrumentos y en el desarrollo de técnicas y en la que los textos sagrados no se ven como si determinasen las posibilidades dentro de

29 La narración me la sugirió la lectura del artículo "Language and Experience" de R.L. Goodstein, en Arthur Danto y Sidney Morgenbesser (comps.), Philosophy of Science, reimpreso del libro de Goodstein, Constructive Formalism: Essays on the Foundations of Mathematics. 
las que podemos reconocer que se están llevando a cabo especulaciones serias. Lo que hace que la oración sea una hipótesis es que está relacionada con las formas como se formulan y se estudian las hipótesis y con los métodos para investigarlas, pensar en ellas, considerarlas, criticarlas, etc. Y así, si decimos de Leibniz que acertó en la edad de los huesos, nuestro mismo comentario tiene más pertinencia que si decimos lo mismo de alguien que emite la oración en la cultura que ha rechazado totalmente la investigación científica.

Entonces, una crítica de Putnam es que la idea de que nosotros tengamos un cuadro de la gente comunicándose entre sí a través del tiempo y a lo largo de las culturas, puede apartar la atención de qué tanto o de cuán poco puede estar contenido en las adscripciones de creencias, creencias especificadas en nuestro lenguaje, para gente que esté distante de nosotros.

\section{XIII}

He aquí mis conclusiones.

Creo que vale la pena poner el énfasis opuesto al de Putnam en la observación de Wittgenstein (Investigaciones filosóficas, § 43) acerca del significado y el uso; que para una gran clase de casos, aun cuando no para todos, en los que empleamos la palabra "significado", ésta puede explicarse de la siguiente manera: el significado de una palabra es su uso en el lenguaje. Putnam subraya que Wittgenstein no está identificando el significado con el uso. Es verdad. Pero está insistiendo en señalar que en un gran número de casos deberiamos intentar pensar en el significado como uso. $\mathrm{Y}$, si hacemos eso, ciertamente nos empujará en la dirección del verificacionismo, ${ }^{30}$ nos llevará a tomar seriamente las diferencias en el uso que subrayan los verificacionistas. Hemos de notar que si una especificación del método de verificación es una aportación a la gramática y si la gramática nos dice de qué estamos hablando, entonces dar un método de verificación es una aportación para determinar de qué estamos hablando. Podemos subrayar estas conexiones en el pensamiento de Wittgenstein sin considerar que está presentando una teoría de la referencia o del significado como determinada por la gramática (mucho menos por la verificación).

Wittgenstein no es ningún verificacionista. Pero, algo que podemos hacer y que Putnam pudo hacer, es tomar en serio el elemento verificacionista que

30 Putnam (en "Meaning Holism", Realism with a Human Face, p. 301), cita las observaciones de Warren Goldfarb acerca del $\S 43$ y expresa su aceptación de su tesis. Goldfarb escribió, "Dado que, por sí mismo, invocar el uso acarrea poca información, considero que la observación [de Wittgenstein] en $\S 43$ es, en gran medida, una negación de la posibilidad y de lo apropiado de teorizar acerca del significado" ("I want you to Bring Me a Slab", p. 279). Mi posición difiere de la de Goldfarb en tanto que yo considero que la invocación del uso en $\S 43$ tiene un contenido importante y que pretende llamar la atención sobre las diferencias en uso que podríamos estar inclinados a pasar por alto en filosofía. 
está presente en sus métodos filosóficos, sin pasar por alto la importancia de la comunicación y de la comprensión entre la gente a lo largo del tiempo y a través de las culturas, que varía de muchas maneras, incluyendo sus técnicas de investigación. Si se acepta ese elemento verificacionista, quizás disminuya la distancia entre Putnam y Rorty. Pero creo que aún hay diferencias significativas y he sugerido una de ellas, a saber, que la versión de Putnam y no la de Rorty, trata como importantes las relaciones reconocidas en nuestra disponibilidad de traducir las oraciones de otros como oraciones de nuestro lenguaje, como expresiones de lo que creeríamos si emitiésemos las mismas palabras. El ejemplo de Putnam de los huesos de Whoozie es particularmente eficaz, en parte porque las conexiones que hacemos aquí entre el especulador y nosotros mismos, reflejan un interés humano compartido por comprender las cosas extrañas que encontramos en el mundo con nosotros. Pero el ejemplo de Putnam nos lleva más lejos.

He hablado de que nuestras palabras concuerdan con las palabras de otros; que se encuentran en relaciones tales como la de expresar creencias iguales o diferentes. Nuestras palabras concordando con las palabras de otros; nuestras palabras concordando con lo que sucede; estas 'concordancias' (es decir, la lógica de la creencia) están configuradas en lo que hacemos, nuestras respuestas a palabras y gestos. "Los conceptos. .. ", dice Wittgenstein, "son la expresión de nuestro interés y dirigen nuestro interés" (Investigaciones filosóficas, § 570). En el análisis de Putnam de los huesos de Whoozie se expresa con claridad y sensibilidad la gran importancia de nuestro interés en "la otra gente" (NTO, p. 4), nuestro interés en comprender y en comunicar. ${ }^{31}$

\section{Apéndice}

\section{Notas tomadas por Margaret Macdonald en la conferencia de Wittgenstein del 18 de noviembre de 1935}

Si se dice que son privados los datos sensoriales, con frecuencia se contrastan con los objetos físicos. Es como poner algún papel transparente entre él y el objeto y dibujarlo en dos dimensiones. En ocasiones estamos tentados a pensar que lo que vemos es un cuadro bidimensional de esta manera. Entonces estamos tentados a decir que lo que vemos no es para nada una silla, sino un

31 Estoy muy agradecida con James Conant y Anthony Woozley por sus comentarios y sugerencias a una versión anterior de este escrito. Mucho aprecio haber tenido la oportunidad de presentar el artículo en el "Simposio de filosofia: en torno a la obra de Hilary Putnam", organizado por el Instituto de Investigaciones Filosóficas de la UNAM. Al preparar esta versión de mi escrito me han auxiliado la muy lúcida respuesta de Hilary Putnam al mismo, en la reunión, así como los comentarios de otros participantes. 
dato sensorial o una visión particular de la silla o algo semejante. Puede haber un espejo que no veo cuando pienso que veo la silla, de tal manera que lo que realmente estoy viendo es una imagen especular. Yo podría señalar que no estamos forzados a decir que vemos lo mismo pero [podríamos decir] que algo parece lo mismo o que la apariencia es la misma con respecto tanto a la imagen especular como al objeto.

Proposiciones como "Esto es verde" (cuando apunto a mi propio dato sensorial y emito estas palabras) las han estudiado Russell y Moore. Nada me impide apuntar y decir las palabras, pero eso es casi todo. Pero Russell y Moore dicen que cuando uno dice esto, uno se está hablando a sí mismo. Esto parece que se toma como una prueba de que hay algún tipo de objeto ahí cuando digo "Esto es verde" - pero no el objeto físico, que es público. La forma "Esto es tal y cual" nos es muy bien conocida. En algunas situaciones en las que usamos la expresión es tautológica, pero parece que tiene muy buen sentido. ${ }^{32}$

Estamos tentados a decir, sea que sepamos o no si él ve rojo, que él lo ve o que no lo ve, aun cuando no tengamos ningún criterio de esto. Compárese esto con la determinación de la velocidad de la luz y los medios para determinar cuándo la luz llegó al espejo. Estamos inclinados a decir, "O bien la luz llegó al espejo en la mitad del tiempo o no lo hizo, aun cuando no tengamos medios para detectar esto..." Este tipo de pregunta nada dice, es una tautología. Pero iqué papel desempeña la tautología? Parece que, cuando se dice "O bien la luz llegó al espejo en la mitad del tiempo o no lo hizo", se estuviese insistiendo en señalar que hay dos alternativas. Pero lo que se hace es insistir en el uso de ciertas expresiones.

Tenemos un cuadro particular que creemos que corresponde con nuestras palabras; tenemos un cuadro de algo que llega a algún lugar en cierto tiempo y decimos que sabemos lo que queremos decir (significamos) al decir que el rayo de luz llega en cierto tiempo. Pero, isabemos cómo usar este cuadro en el caso particular que estamos estudiando? La luz se compara a cierto tipo de Mensajero. Entonces, estamos usando una especie de cuadro que casi nos obliga a ir de cierta manera. Yo no puedo hablar acerca de la luz como un 'Mensajero' sin decir que tiene sentido decir que él llegó a cierto lugar en cierto tiempo. Todo lo que tenemos es una lámpara, un espejo y cierta sensación de luz. Pero pensamos en el experimento en términos de lanzar una bola y de que la bola rebote de nuevo. Pero, realmente, nada fue lanzado y nada regresa. Pero la idea de una superficie que 'rebota' la luz nos es muy familiar. Pero, si proseguimos con este cuadro, entonces decir que no tiene sentido preguntar en qué momento llegó la luz al espejo, hace estragos en nuestros pensamientos. Tenemos que abandonar el cuadro. Señalar que no tiene sentido decir 
que la luz llegó en cierto momento, comprende también que no tiene sentido decir que llegó en un momento entre dos límites. Pero, se podría decir, no estamos tratando con momentos sino con extensiones de tiempo (el hombre con un reloj); pero esto nada modifica.

Imágenes residuales. Podríamos decir que una cosa le es favorable a la noción de datos sensibles, a saber, el hecho de las imágenes residuales. Se podría decir: una imagen residual es privada. Yo no puedo tener su imagen residual. ¿En qué consistiría que yo tuviera su imagen residual?

La pregunta, "¿En qué consistiría que tal y cual cosa sucediera?” siempre se formula con respecto a la eliminación de cierto tipo de problema. Si alguien dice, “'En qué consistiría el que alguien se sentase en una silla?”, yo preguntaría, ¿qué es lo que pretendes (significas) al formular esa pregunta? ¿Qué tipo de cosa quieres que se te explique - cuál es tu problema? De ordinario, sabemos qué es lo que quiere decir (significa) el que alguien se siente en una silla; no hay dificultad acerca de esto. Simplemente se sienta en la silla y eso es todo. $\mathrm{O}$, ime estás pidiendo que pinte un cuadro de alguien sentado en una silla? O bien, ¿están sus piernas tiesas de tal manera que no sabes qué es lo que hará con ellas cuando se siente en la silla? Compárese esto con preguntar en qué consistiría esperar a alguien de 4 a 4:30. ¿Es preguntar si hay un estado mental peculiar que dura de las 4 a las $4: 30$, si son diferentes actividades o qué es lo que es? Usualmente esto comprende diversas posibilidades alternativas como si, p. ej., uno pudiese sentarse en una silla de muchas maneras diferentes.

Si preguntas "¿En qué consistiría tener la misma imagen residual que otro?" se podría preguntar, "२Qué tipo de explicación quieres?" Debemos decir qué tipo particular de problema deseamos resolver y qué comparaciones hay que hacer. Debemos comparar esto con el caso en el que normalmente diríamos que vemos 'el mismo tal y cual'. Deseamos saber el uso de "mismo" en, p. ej., "Veo la misma silla", "Veo el mismo color" o "Veo la misma imagen residual" que él. ¿Cuál es el criterio para que ésta sea la misma silla que vi ayer? Puedo tener dos sillas que se vean exactamente iguales, quitarlas de tu vista, luego traerlas de nuevo y, apuntando a una, decir "¿Es ésta la silla en la que te sentaste?" En estas circunstancias no habría ninguna respuesta a esta pregunta; no tendría ningún sentido. Compárese el caso de los dos ríos que fluyen uno en el otro y uno continúa. ¿Cuál es el que continúa? Si un arroyo fluye al Danubio, estaríamos tentados a decir que es el Danubio el que prosigue y no el arroyo. Pero supóngase que dos ríos se unen y prosiguen con un nuevo nombre; entonces podemos decir que idos han desaparecido y uno no tiene fuente! Uno puede imaginar gente que, en tales casos, diría, "Bueno, o bien es el mismo río o no lo es, aun cuando no podamos descubrir esto". Esto sería un sinsentido. ¿Cómo se están usando las palabras "Es o no lo es"? 
¿Cuál es el criterio para el caso de las inágenes residuales? ‘Podemos decir, "Vi la misma imagen residual en dos ocasiones diferentes"? Si vemos el sol y luego apartamos la vista, veo una imagen residual; y si veo una luz eléctrica, veo una imagen residual del mismo tipo, aun cuando usualmente digo que son dos [imágenes residuales] diferentes, aunque exactamente iguales. 'Cómo comparamos dos imágenes residuales? Podríamos describirlas o pintar un cuadro de ellas. Pero, igualmente, la gente podría decir "Sea como sea que las compares, o bien tienes la misma imagen residual o no la tienes". ( Hemos de considerar la mismidad de las imágenes residuales como una meta inalcanzable, a la que podemos aproximarnos pero nunca alcanzar?) -Puedes escoger cualquiera de las dos. Lo central es que usamos la palabra "mismo" de manera muy diferente. Decir "O bien vemos la misma cosa o no la vemos", es insistir en apuntar a un tipo especial de imaginería. Éste sugiere ver dos cuadros que o bien son similares o no lo son. No objeto esto, pero hay que tener cuidado acerca de la aplicación, porque los casos son muy diferentes. Debes dar la gramática de un cuadro, así como la de una palabra u oración; debes decir cómo vas a usar el cuadro.

Compárese el caso de mirar hacia afuera de la ventana y ver una precipitación pluvial. La gente diría que debe haber cierto número de gotas, aun cuando no podamos contar el número y debemos estar viendo precisamente ese número. Esto parece como si debiera haber una respuesta a ¿Cuántas gotas hay?" Éste es un caso en el que cualquier cosa que digas es probable que choque con alguna otra cosa que digas. Compárese el caso de una aritmética primitiva que tenga " 1 ", " 2 ", " 3 ", " 4 ", " 5 " y "muchos" para cualquier cosa por encima de 5. Tú quieres decir que "muchos" es una expresión de ignorancia (pero no necesariamente es así). Supóngase que alguien pregunta, "¿Cuántos cabellos tiene él en su cabeza?" Probablemente "un montón", no "99" o cualquier otro número definido.

Vemos qué es lo que nos hace decir que las imágenes residuales son 'esencialmente privadas' y "Sólo yo puedo saber qué imágenes residuales tengo". Podríamos pensar que nuestra gramática muestra esto y revela una diferencia en la 'naturaleza' de los objetos físicos y de las imágenes residuales, pero no es así.

Extracto de las notas tomadas por Margaret Macdonald en la conferencia de Wittgenstein del 21 de enero de 1936

(El siguiente material está entre paréntesis en el manuscrito de Margaret Macdonald y tiene sus iniciales al final, lo cual sugiere que ese párrafo o alguna parte de él pudo haber sido reconstruido por ella, a partir de esbozos de notas.) 
Poner, como una definición ostensiva, un manchón de color al lado de la palabra "rojo", aún no te obliga a que llames rojas a las fresas o a la sangre, etc. Esto es algo que haces posteriormente y, de hecho, $l o$ haces. Decir que lo haces porque hay una relación interna de similitud entre las cosas que llamas rojas es dar otra regla de gramática para "rojo"; de las cosas que, de hecho, llamas rojas, siempre vas a decir que están relacionadas por la relación interna de 'ser similar en color'. Y tú podrías usar "rojo" tanto para la sangre como para Do mayor y el olor de lavanda -así como ahora lo usas para muchos diferentes matices de rojo, cuando no deberías hacerlo- pero si tu uso se hace muy errático, no diremos, de manera alguna, que estás usando una palabra en un lenguaje. El uso, p. ej., debe conformarse a tus reglas...

Traducción de José A. Robles 